\title{
NEUROPROTECTIVE EFFECTS OF Buchholzia coriacea SEED EXTRACT ON SODIUM AZIDE-INDUCED NEUROTOXICITY OF THE PREFRONTAL CORTEX OF WISTAR RATS
}

\author{
Abayomi T.A ${ }^{1}$, Tokunbo 0.S ${ }^{1}$, David 0 ${ }^{1}$, Obembe 0.0 ${ }^{2}$, Dare B.J ${ }^{1}$ \\ ${ }^{1}$ Department of Anatomy, Faculty of Basic Medical Sciences, College of Health Sciences, Osun State \\ University, PMB 4494, Osogbo, Osun State, Nigeria. \\ ${ }^{2}$ Department of Physiology, Faculty of Basic Medical Sciences, College of Health Sciences, Osun State \\ University, PMB 4494, Osogbo, Osun State, Nigeria.
}

Correspondence to Dr Abayomi Taiwo A., Department of Anatomy, Faculty of Basic Medical Sciences, College of Health Sciences, Osun State University. Osogbo. Osun State. Email: taiwo.abayomi@uniosun.edu.ng. Phone number: +2348164375232

\begin{abstract}
This study was designed to evaluate the therapeutic potentials and neuroprotective effects of methanol extract of Buchholzia coriacea (BC) seeds on sodium azide $\left(\mathrm{NaN}_{3}\right)$ induced neurotoxicity of the prefrontal cortex in male Wistar rats. Neurotoxicity occurs as a result of exposure to neurotoxins in the environment, of which $\mathrm{NaN}_{3}$ is a potent neurotoxin. Thirty male Wistar rats were were randomly divided into 5 groups. Group A were administered with distilled water. Group B was administered with $\mathrm{NaN}_{3}$ for 28 days. Group C was administered with $\mathrm{NaN}_{3}$ for 28 days and thereafter $B$. coriacea for 21 days. Group D was administered with B. coriacea for 21 days and then $\mathrm{NaN}_{3}$ for 28 days. Group $\mathrm{E}$ was administered with only B. coriacea for 21 days. After treatment, neurobehavioral assessment was carried out after which the rats were sacrificed, and the prefrontal cortex excised. The prefrontal cortex was then processed for histological and biochemical analysis (SOD, MDA, GSH, and CAT). Pre-treatment and post-treatment with Buchholzia coriacea revitalized the cells of the Prefrontal cortex which were damaged by $\mathrm{NaN}_{3}$ exposure. Oxidative stress levels also decreased as a result of $B$. coriacea treatment, suggesting neuroprotective effects of Buchholzia Coriacea.
\end{abstract}

Keywords: Buchholzia coriacea, Sodium Azide, Neurodegeration, Prefrontal cortex

\section{INTRODUCTION}

Neurotoxicity occurs with exposure to natural or artificial toxic substances called neurotoxins, such as those used in chemotherapy, radiation treatment, drug therapies, certain drug abuse, and organ transplants, as well as exposure to heavy metals, certain foods and food additives (Robert, 1996), pesticides (Engel et al., 2001), industrial and/or cleaning solvents, cosmetics, and some naturally occurring substances. Symptoms may appear immediately after exposure or be delayed which alters the normal activity of the nervous system causing damage to nervous tissue, eventually disrupting or even killing neurons. Neurotoxicity has been found to be a major cause of neurodegenerative diseases such as Alzheimer's disease (AD).

Neurodegenerative diseases affect millions of people all over the world. Neurodegenerative diseases occur when nerve cells in the brain or peripheral nervous system lose function over time and ultimately die, thereby impeding affected individuals from living normally (Enciu et al., 2011). There are currently no therapies available to cure neurodegeneration. For each of the diseases, medication can only alleviate symptoms and help to improve patients' quality of life. Research progresses in understanding the 
molecular mechanisms involved in neurodegenerative disorders.

Sodium azide $\left(\mathrm{NaN}_{3}\right)$ is the inorganic compound with the formula $\mathrm{NaN}_{3}$. It is acutely neurotoxic and has caused deaths for decades (Smith et al., 1991). Studies carried out on the substance implicated it as neuronal mitochondrial toxin (Chang et al., 2011). Local or systemic administration of $\mathrm{NaN}_{3}$ induces the release of excitotoxins via mitochondria energy machinery impairment leading to neuronal cell loss (Luques et al., 2007). The metabolic and cellular disruptions which can be induced by $\mathrm{NaN}_{3}$ are also linked with synaptic denervation, cell loss and behavioural deficits in several disease conditions involving Neurodegeneration (Ahmed and Farouk, 2013). The most common form of cell death in neurodegeneration is through the intrinsic mitochondrial apoptotic pathway (Rego and Oliveira, 2003). This pathway controls the activation of caspase- 9 by regulating the release of cytochrome $c$ from the mitochondrial intermembrane space (IMS). Reactive oxygen species (ROS) are normal by products of mitochondrial respiratory chain activity. ROS concentration is mediated by mitochondrial antioxidants such as manganese superoxide dismutase $\left(\mathrm{SOD}_{2}\right)$ and glutathione peroxidase. Over production of ROS (oxidative stress) is a central feature of all neurodegenerative disorders. mitochondrial toxin such as sodium azide $\left(\mathrm{NaN}_{3}\right)$, induces a hypoxic-like condition through its ability to inhibit the electron transfer between cytochrome c oxidase (mitochondrial complex IV) and oxygen (Leary et al., 1998;
Duranteau et al., 2002; Safiulina et al., 2006), and reversibly increases intracellular $\mathrm{Ca}^{2+}$, at least partially involving N-Methyl-D-Aspartic acid (NMDA) glutamate receptor activation (Marino et al., 2007). The features of the neuronal damage induced by treatment with $\mathrm{NaN}_{3}$, which to date remain not completely known, involve both necrotic and apoptotic cell death (Hoyagi et al., 2000; Grammatopoulos et al., 2002).

Buchholzia coriacea ( $B$. coriacea) popularly known as wonderful kola belongs to the family Capparaceae and is widely distributed in several tropical countries. Its leaves and seeds are reputed scientifically to have good Antihelmintic (Ajaiyeoba et al., 2001), antibacterial (Mbata et al., 2009), antimicrobial (Ezekiel and Onyeoziri, 2009), hypoglycaemic (Adisa et al., 2011), antimalarial (Okolie et al., 2010), abortifacient and cytotoxicity effects (Adjanohoun et al., 1996). Exploring the therapeutic potentials of $B$. coriacea hopes to offer medicinal options that could protect the nervous system from neurotoxicity, and subsequently, neurodegenerative diseases. However, there has been little or no scientific evidence on the effects of $B$. coriacea on the brain.

Thus, we evaluated the effects of $B$. coriacea on $\mathrm{NaN}_{3}$-induced cognitive and memory impairment. Biomarkers of oxidative stress were also examined by assaying for superoxide dismutase (SOD), malondialdehyde (MDA), catalase (CAT) and Gluthathione (GSH) enzymes. Finally, the histology of the prefrontal cortex of the rats were observed.

\section{MATERIALS AND METHODS}

All protocols and treatment procedures were done according to the Institutional Animal Care and Use Committee (IACUC) guidelines and as approved by the Faculty of Basic Medical Sciences Ethics Review Committee, Osun State University, Nigeria. Thirty (30) adult male Wistar rats with an average weight of $140 \mathrm{~g} \pm 10 \mathrm{~g}$ were purchased and housed in the animal house of the Faculty of Basic Medical Sciences, Osun State University. The rats had liberal access to rat chow and water.
The rats were randomly assigned into 5 groups $(A-E)$ with six rats each. Group A rats received the vehicle (distilled water only) and was the positive control. Group B were administered $\mathrm{NaN}_{3}(17 \mathrm{mg} / \mathrm{kg}$ ) for 28 days and was the negative control group. The rats in group $\mathrm{C}$ $\left(\mathrm{NaN}_{3}+\right.$ B. coriacea) were given $\mathrm{NaN}_{3}$ for 28 days and then treated with $B$. coriacea $(100 \mathrm{mg} / \mathrm{kg})$ for 21 days. The Rats in group $D(B$. coriacea+ $\mathrm{NaN}_{3}$ ) were pre-treated with $B$. Coriacea (100 $\mathrm{mg} / \mathrm{kg}$ ) for 21 days followed by $\mathrm{NaN}_{3}$ for 28 days. 
The rats in group $E$ were administered with 100 $\mathrm{mg} / \mathrm{kg}$ of $B$. coriacea only for 21 days. $\mathrm{NaN}_{3}$ was administered subcutaneously using $1 \mathrm{ml}$ insulin syringe while $B$. coriacea was administered orally using an oral cannula. All treatment was done daily by 9am. After administration, neurobehavioral tests were conducted on each rat for 3 consecutive days.

Methanol extract of $B$. coriacea seeds were prepared as earlier described (Obembe et al., 2012). Briefly, the clean shade-dried seeds were pulverized. The powdered seeds $(2.36 \mathrm{~kg})$ were macerated in methanol $(80 \% \mathrm{v} / \mathrm{v})$ for 15 days with daily shaking. The solvent was decanted every five days and each time replaced with fresh solvent. The extract obtained was concentrated to a dark-brown residue on a rotary evaporator at $40^{\circ} \mathrm{C}$ and weighed. The Methanol Extract of Seeds of $B$. Coriacea (MEBC) obtained was concentrated to dryness (93.02 g) by lyophilization. Percentage yield was $3.94 \%$.

Novel object recognition is a highly validated test for recognition memory. It can be used to test the efficacy of memory enhancing compounds, the negative effects of certain other compounds on memory, the influence of genetics or age on memory (Taglialatela et al., 2009).

The principle is that rats are exposed to two or more objects and gets to explore these for a while. Then one of the objects is replaced by another one. If the memory is functioning normally, the rat will spend more time exploring this novel object than it does exploring the familiar objects (Ennaceur, 2010). If exploration of all objects is the same, this can be interpreted as a memory deficit.

The NOR was performed in a $40 \times 60 \mathrm{~cm}$ box made of wood. The recognition objects are made of Plastics. Before starting the trainings, the animals had two exploration sessions for contextual habituation, with no objects inside the box.

The rats were allowed to explore two different objects for duration of 5 minutes. The objects had a neutral shape and lacked any marked characteristics, such as odour and movement. Both were positioned in the box centrally, at least $10 \mathrm{~cm}$ from the side wall to avoid touching during the first object exploration. The total time spent exploring the two objects was recorded with the use of two stopwatches. Object recognition is defined as directing the nose and vibrissae to the objects at a distance of less than $2 \mathrm{~cm}$, as if smelling cautiously; bumping, turning around or sitting on the object are not considered exploratory behaviours. After the training trial, the animal was moved from the box and returned to its home cage.

After a period of 15 minutes, the animal was reintroduced into the box for the test session (choice phase), now with a different set of objects- one familiar (identical to, but not the same one previously explored), and the other which is a new unexplored object- both placed in the same position as the sample stimuli.

According to the phase analysed, two indexes was used: a discrimination index: the difference in the time spent exploring each of the two objects in the choice phase (i.e., time with $B$ minus time with $A$ ), and the discrimination ratio, which is the difference in exploration time, expressed as the ratio of total exploration time with both objects in the choice phase.

On completion of treatments, rats for histological analysis were euthanized using $20 \mathrm{mg} / \mathrm{kg}$ of ketamine (intraperitoneal). Transcardial perfusion was done by exposing the left ventricle and injecting $50 \mathrm{ml} 0.1 \mathrm{M}$ PBS (pH 7.4) followed by $400 \mathrm{ml} 4 \%$ paraformaldehyde (PFA) while the rat was suspended in an inverted position (gravity). Excised brains were then rinsed in 0.25 $M$ sucrose 3 times for 5 minutes each and then post fixed in 4\% PFA for 24 hours before being stored in $30 \%$ sucrose at $4{ }^{\circ} \mathrm{C}$ until further processing. Rats for enzymatic assays were sacrificed by separating the head from the trunk to avoid the interference of ketamine with biochemical redox; brains were then excised, rinsed in $0.25 \mathrm{M}$ sucrose 3 times for 5 minutes 
each and placed in $30 \%$ sucrose in which they were stored at $4^{\circ} \mathrm{C}$. Coronal sections of the prefrontal cortex (PFC) were obtained stereotaxically $(+4 \mathrm{~mm})$ from each brain. Histological staining was carried out in paraffin wax embedded sections which were stained with Haematoxylin and Eosin using the methods described by Fischer et al (2008). Histochemical demonstration of Nissl substances was done with slight modification to the method published by Kádár et al (2009). Sacrifice of the animals was done in batches based on the duration and treatments of animals in each group.

Determination of Superoxide dismutase (SOD), Catalase (CAT), Glutathione (GSH), and Malondialdehyde (MDA) activities was carried out on the homogenized prefrontal cortices of treated rats using spectrophotometric technique. Each of the assay kits were procured from Bio Legend Inc., San Diego, CA, USA. The prefrontal cortex in sucrose at $4^{\circ} \mathrm{C}$ ) from rats across groups were weighed and pulverized in $0.25 \mathrm{M}$ sucrose (Sigma) with the aid of an automated homogenizer at $4^{\circ} \mathrm{C}$. Lysates from the brain were centrifuged for 10 minutes in a microfuge at
$12,000 \mathrm{rpm}$ to obtain the supernatant containing organelle fragments and synaptosomes. The supernatants were aspirated into plain labelled glass cuvette placed in ice. SOD, CAT, TAC, and MDA activities were assayed according to the manufacturer's instruction in the assay kit pack.

Prefrontal cortices sections on glass slides were captured using Olympus binocular research microscope (Olympus, New Jersey, USA) which was connected to a 5.0MP Amscope Camera (Amscope Inc, USA).

All quantitative data were analyzed using GraphPad Prism \& (version 6) and SPSS (version 20) softwares. Neurobehavioral assessments, catalase (CAT), Glutathione (GSH), malondialdehyde (MDA), and superoxide dismutase (SOD) outcomes were plotted in ANOVA followed with Tukey's multiple comparisons test. Significance was set at $\mathrm{p}<0.05^{*}, \mathrm{p}<0.01^{* *}$ and $\mathrm{p}<0.001^{* * *}$. The results were represented in bar charts with error bars to show the mean and standard error of mean (Mean \pm SEM) respectively.

\section{RESULTS}

Subjecting the result of the test to statistical analysis revealed a significant decrease $(p<0.05)$ in the time spent exploring the novel object by $\mathrm{NaN}_{3}$ treated rats when compared with the control (Fig. 1). However, B. Coriacea extract $\left(100 \mathrm{mg} / \mathrm{kg}\right.$ ) reversed the $\mathrm{NaN}_{3}$-induced decrease in time spent by the rats exploring the novel object.
Differential expression of SOD and CAT were assessed in the prefrontal cortex of treated rats (Fig. 2 and 3 respectively). Our results show significant increase $(p<0.05)$ in activities of catalase (CAT) and super oxide dismutase (SOD) in all $B$. coriacea $(100 \mathrm{mg} / \mathrm{kg})$ treated rats when compared to the $\mathrm{NaN}_{3}$ group. Rats treated with $\mathrm{NaN}_{3}$ expressed significantly decreased levels in the activities of these enzymes. 


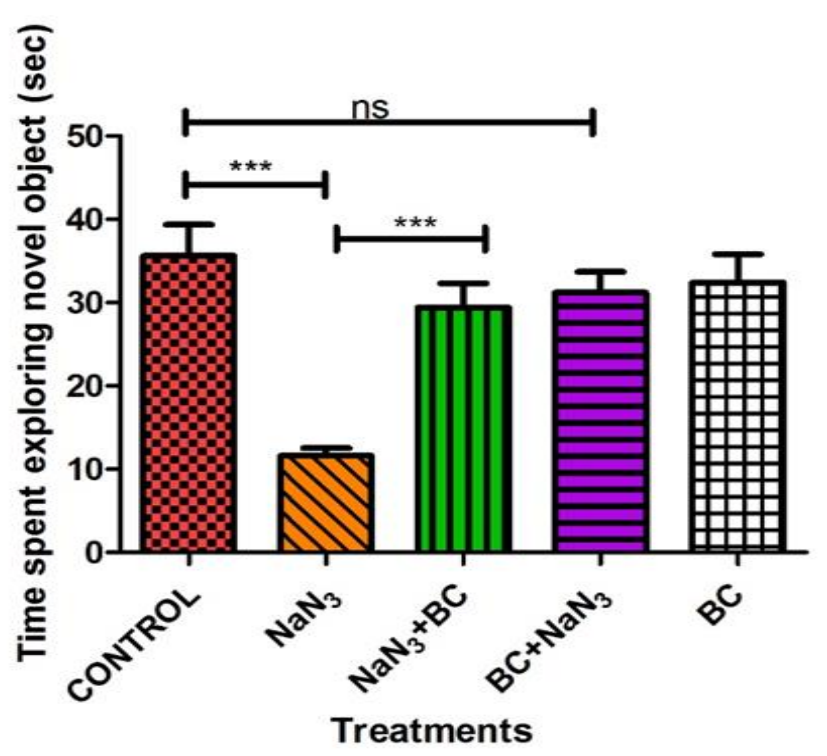

Fig 1: Chart showing novel object recognition test for spatial memory of $\mathrm{NaN}_{3}$ and $B$. coriacea treated rats. $* * *$ indicates $\mathrm{p} \leq 0.01, \mathrm{n}=6, \mathrm{BC}-B$. coriacea.

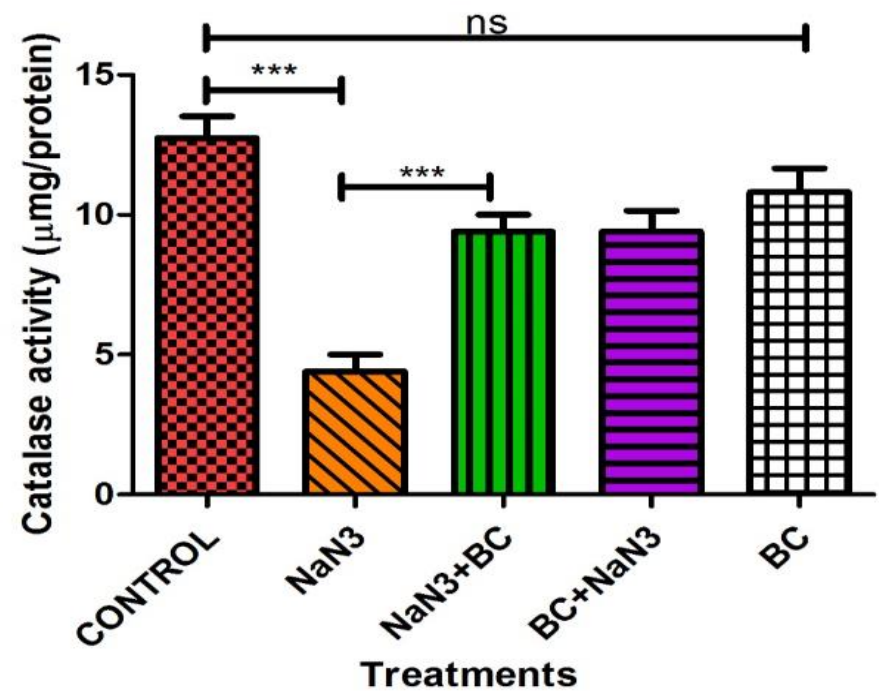

Fig 3: Chart showing the levels of catalase in the prefrontal cortex of $\mathrm{NaN}_{3}$ and $B$. coriacea treated rats. $* * *$ indicates $\mathrm{p} \leq 0.001, \mathrm{n}=6, \mathrm{BC}-$ B. coriacea.

$\mathrm{NaN}_{3}$ caused a significant decrease in the GSH activity in the prefrontal cortex of treated rats when compared with the control (Fig 4). The level of this enzyme was not affected by the $B$. coriacea treatment. However, B. coriacea

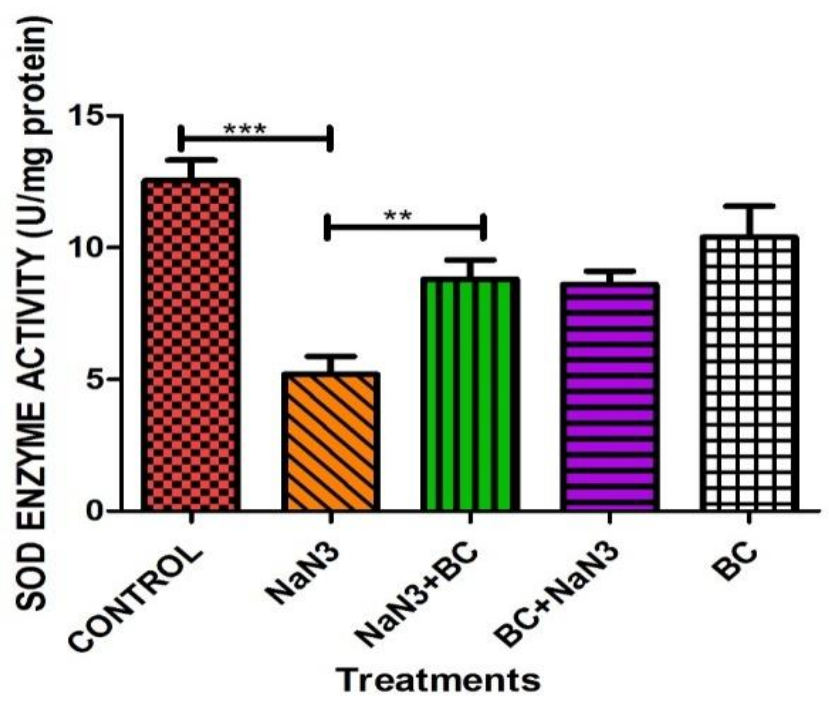

Fig 2: $\mathrm{SOD}$ levels in the prefrontal cortex of $\mathrm{NaN}_{3}$ and $B$. coriacea treated rats. $* *$ indicates $\mathrm{p} \leq 0.01$, $* * *$ indicates $\mathrm{p} \leq 0.001, \mathrm{n}=6, \mathrm{BC}-B$. coriacea.

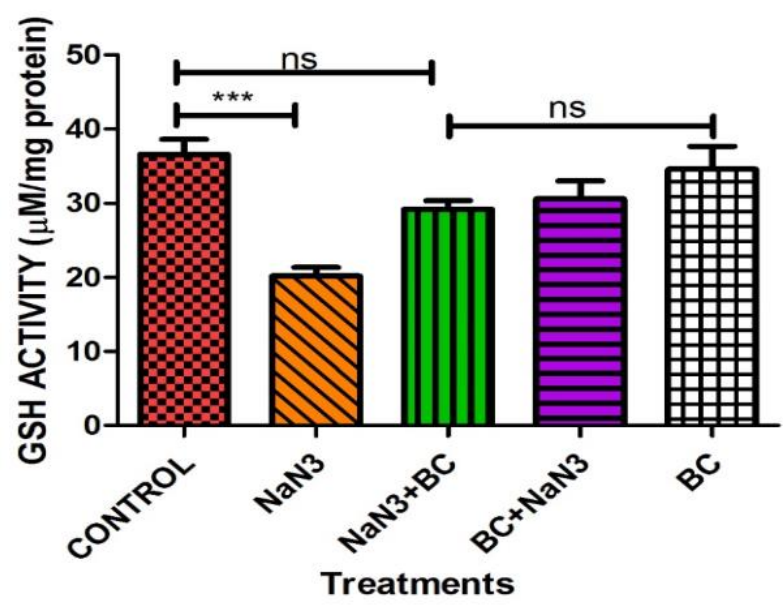

Fig 4: Chart showing the levels of GSH in the Prefrontal cortex of $\mathrm{NaN}_{3}$ and $B$. coriacea treated rats. $* * *$ indicates $\mathrm{p} \leq 0.001, \mathrm{n}=6, \mathrm{BC}-\mathrm{B}$. coriacea.

significantly ameliorated the $\mathrm{NaN}_{3}$ induced decrease in GSH activity in either treatment regimen. All groups treated with $B$. coriacea had significantly higher GSH levels in the prefrontal cortex than the $\mathrm{NaN}_{3}$ treated group. 
Malondialdehyde level significantly increased in the prefrontal cortex of rats treated with $\mathrm{NaN}_{3}$ when compared with the control group. Rats treated with $B$. coriacea had significantly lower MDA level when compared with $\mathrm{NaN}_{3}$ group. $B$. coriacea reversed and prevented the $\mathrm{NaN}_{3}-$ induced increase in MDA levels in the prefrontal cortex of rats.

Rats of the control and B. coriacea groups had normal panoramic morphological presentation of the PFC layers (yellow arrows) at various exposures and magnifications (figure 6-8). The well outlined array of cells within the PFC can be observed distinctly arranged from the Layer I-V. In addition, cellular density within these groups appears normal across all the cortical layers with appreciable spines and neuronal projections (yellow arrows). Sodium azide treatment on the other hand, showed severe degenerative changes in the cortex and was characterised by fragmented pyramidal and granule cell layer with observable pyknotic cells (black arrows). Also, there appeared to be a comparative increased cell density in the cortical layers of this group $\left(\mathrm{NaN}_{3}\right) \quad \mathrm{NAN}_{3}+$ wonderful kola as well as wonderful kola $+\mathrm{NAN}_{3}$ treatments (yellow arrows) showed marked regeneration, reduced vacuolation and distinct processes with less blending in the perikarya cytoplasm (fig. 7 and 8).

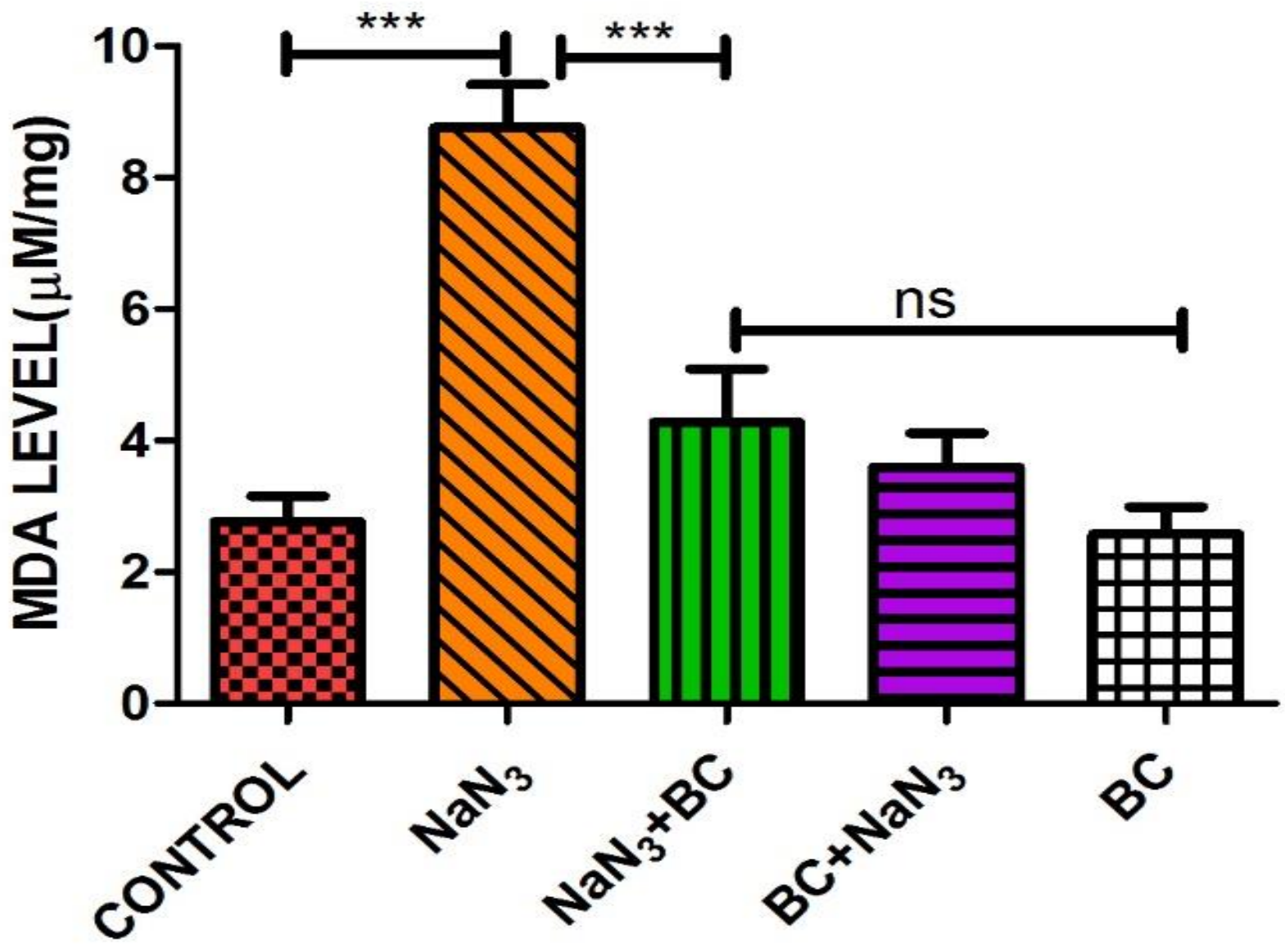

Treatments

Fig 5: Chart showing the levels of MDA in the brain of rats. $\mathrm{NaN}_{3}$ and $B$. coriacea treated rats. $* * *$ indicates $\mathrm{p} \leq 0.001, \mathrm{n}=6, \mathrm{BC}-$ B. coriacea. 

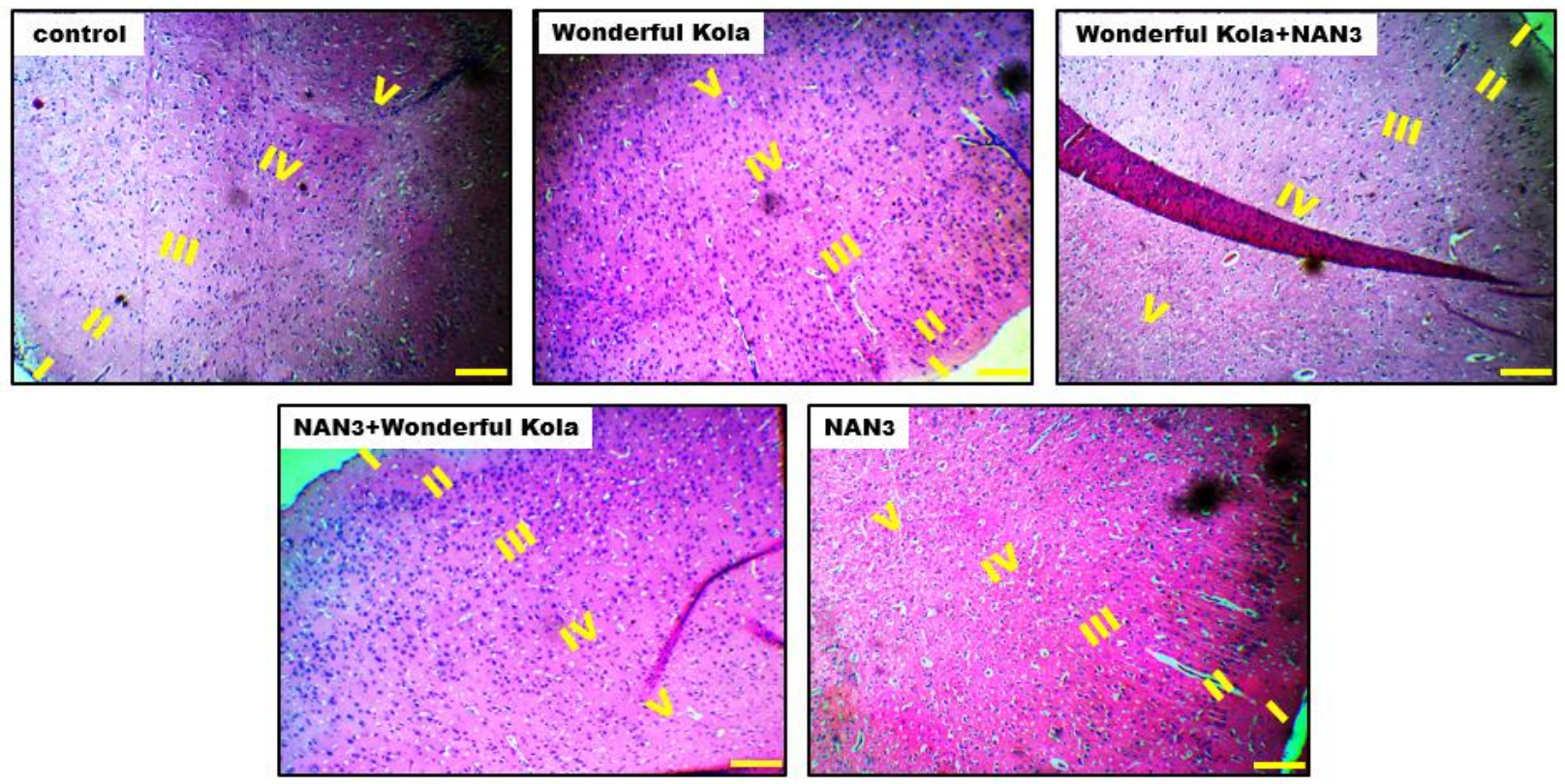

Fig 6: Photomicrograph showing cytoarchitectural arrangement of prefrontal cortex general histomorphological presentations in Wistar rats across the study groups. Hematoxylin and Eosin stain The molecular layer (I), External granular layer (II), External pyramidal layer (III), Internal granular layer (IV) and Internal pyramidal layer (V) are demonstrated cross study groups. (Scale bars: $400 \mu \mathrm{m})$.
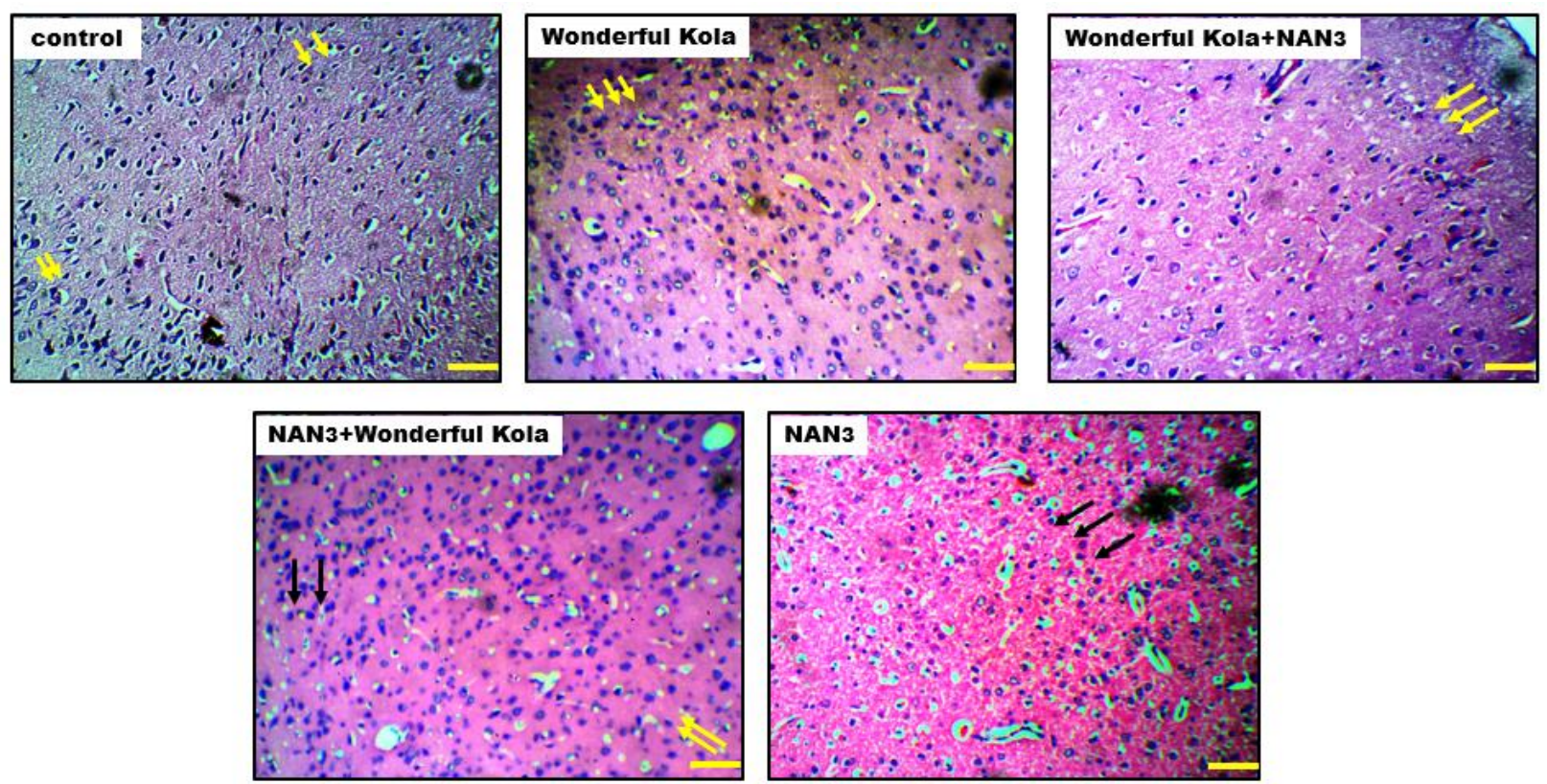

Fig 7: Photomicrographs showing cytoarchitectural arrangement of prefrontal cortex general histomorphological presentations in Wistar rats across the study groups. Hematoxylin and Eosin stain. The molecular layer (I), External granular layer (II), External pyramidal layer (III), Internal granular layer (IV) and Internal pyramidal layer (V) are demonstrated across study groups. (Scale bars: $50 \mu \mathrm{m})$ 

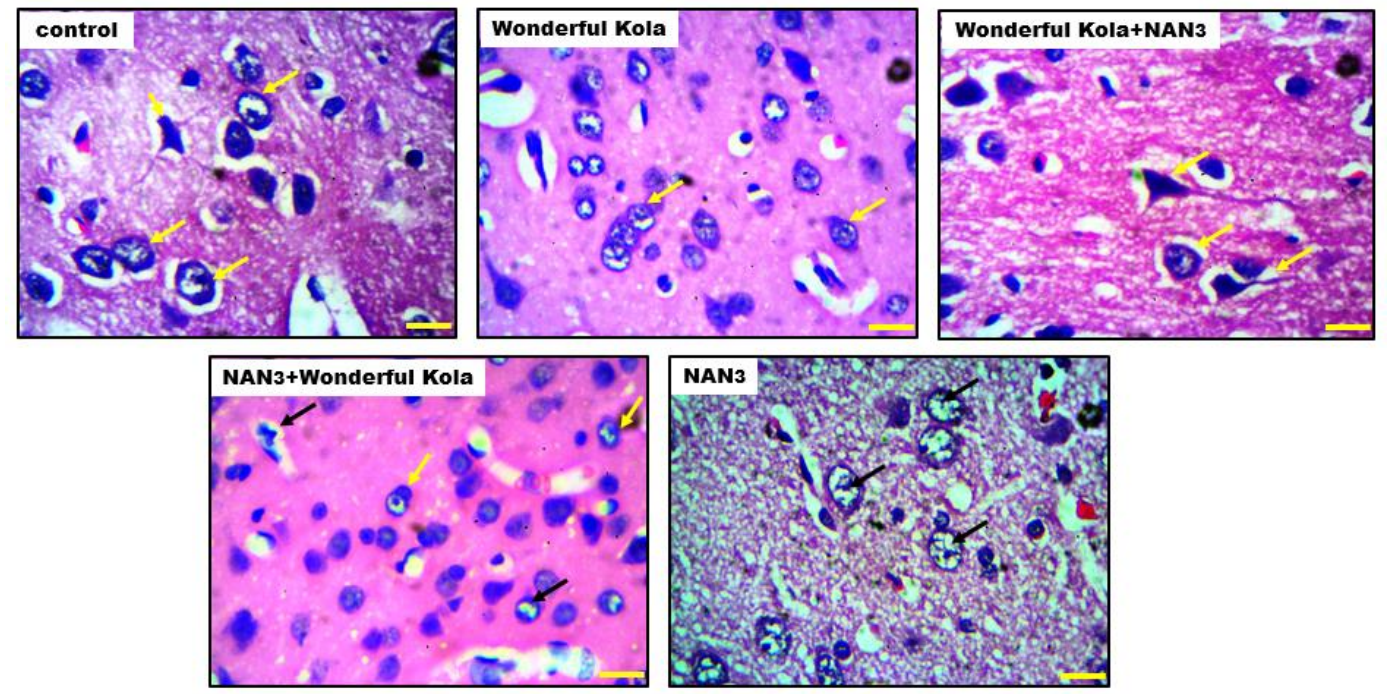

Fig 8: Photomicrographs showing cytoarchitectural arrangement of prefrontal cortex general histomorphological presentations in Wistar rats across the study groups. Hematoxylin and Eosin stain. The molecular layer (I), External granular layer (II), External pyramidal layer (III), Internal granular layer (IV) and Internal pyramidal layer (V) are well demonstrated across study groups. (Scale bars: $25 \mu \mathrm{m}$ )

Nissl profile demonstration by cresyl fast violet (CFV) stain (scale bars $50 \mu \mathrm{m}$ ) across PFC sections within the study groups shows normal morphological presentations in CONTROL and B. coriacea that is characterized with normal and densely populated Nissl proteins, well stained and outlined neurons (yellow arrows). $\mathrm{NAN}_{3}$ treatments caused severe chromatolytic changes as well as some pyknotic changes in both the pyramidal and granule cell layers with a gross reduction in the cytoplasmic Nissl proteins (black arrows). Comorbid treatments with wonderful kola show mild degenerative changes but on a general outlook show a similar morphological presentation with control and wonderful kola treatments.
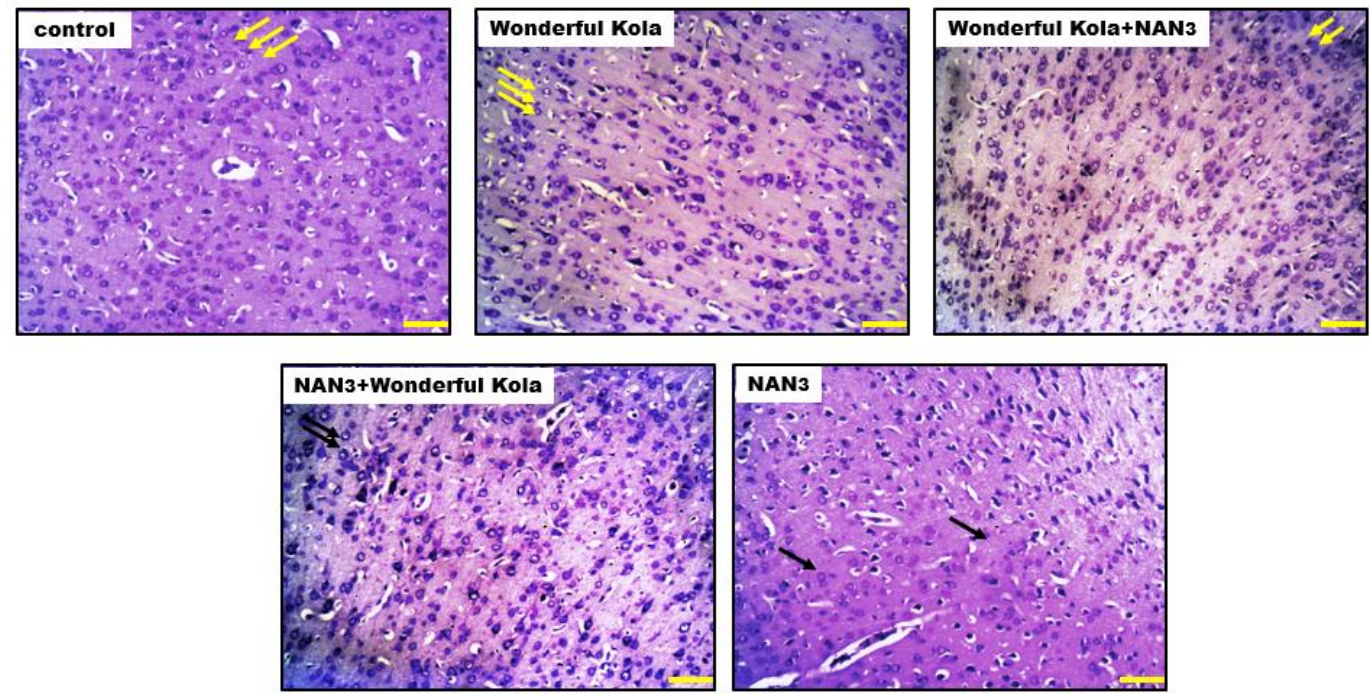

Fig 9: Photomicrographs showing cytoarchitectural arrangement of prefrontal cortex general histomorphological presentations in Wistar rats across the study groups. Cresyl fast violet stain. The molecular layer (I), External granular layer (II), External pyramidal layer (III), Internal granular layer (IV) and Internal pyramidal layer (V) are well demonstrated across study groups. (Scale bars: $50 \mu \mathrm{m}$ ) 


\section{DISCUSSION}

Measuring behavioural outcomes represent an important means of evaluating treatment effectiveness (Jacobson and Truax, 1991). As a correlative test for cellular, molecular and neuropathological changes within the PFC in this study, we assessed cognition and memory in treated rats using the novel object recognition test. The NOR task is very useful to study shortterm memory, intermediate-term memory, and long-term memory, through manipulation of the retention interval, i.e., the amount of time animals must retain memory of the sample objects presented during the familiarization phase before the test phase, when one of the familiar objects is replaced by a novel one (Taglialatela et al., 2009). The result of the test revealed a significant reduction in the time spent exploring the novel object by $\mathrm{NaN}_{3}$ treated rats when compared with the control group. The rats treated with $100 \mathrm{mg} / \mathrm{kg}$ body weight of $B$. coriacea were relatively at par with the control group. They successfully identified the familiar object, and spent more time exploring the novel object. The results gotten instigated that $\mathrm{NaN}_{3}$ could have caused a lesion to the medial prefrontal cortex, and a possible alteration of normal mitochondrial redox and glucose bioenergetics, leading to memory impairment, as confirmed in the study carried out by Jo et al., (2007) and Olayemi et al., (2016). However, B. Coriacea extract $\left(100 \mathrm{mg} / \mathrm{kg}\right.$ ) reversed the $\mathrm{NaN}_{3}$ -induced decrease in time spent by the rats exploring the novel object suggesting that it had a beneficial effect on the cortico-hippocampal dependent cognition and working memory.

The biochemical indices monitored in the brain are useful "markers" for assessment of tissue integrity. The measurement of activities of various enzymes in the tissues and body fluids plays significant role in disease investigation and diagnosis. Tissue enzymes can also indicate tissue cellular damage caused by chemical compounds in the extract long before structural damages that can be picked by conventional histological techniques.
Malondialdehyde (MDA) is a marker for lipid peroxidation. Lipid peroxidation is the oxidative degradation of lipids. It is the process in which free radicals depletes electrons from the lipids in cell membranes, resulting in cell damage. From the result, Lipid peroxidation study showed that rats that received $\mathrm{NaN}_{3}$ only (group $\mathrm{B}$ ) showed significant increase in molindialdehyde (MDA) levels when compared to the control group. MDA levels were significantly low in other treated groups ( $C, D$ and $E$ ) when compared to group $B$. This result is suggestive of absence of oxidative degradation of the phospholipid-bilayered cell membrane through the generation of free radicals and oxidative stress in animals that received $B$. Coriacea. The decrease in the level of MDA in the prefrontal cortices of rats treated with $B$. Coriacea is consistent with studies carried out on the antioxidant properties of $B$. Coriacea as reported by Lapshak et al., (2016).

Superoxide Dismutase (SOD) serves a key antioxidant role. SOD decrease reactive oxygen species generation and oxidative stress and inhibits endothelial activation and indicate that modulation of factors that govern adhesion molecule expression and leukocyte-endothelial interactions. SOD level when evaluated shows a statistically significant increase in rats treated with $B$. Coriacea when compared with rats that received $\mathrm{NaN}_{3}$. Thus, the increase in the SOD level in the treated groups is an indication that administration of $100 \mathrm{mg} / \mathrm{kg}$ body weight of $B$. Coriacea have a protective effect on tissue against oxidative damage which agrees with Moghadamtousi et al., (2015b) stating that elevated activity of SOD protect tissue against oxidative damage to accelerate wound healing process. There was also significant increase in the level of catalase activity in the prefrontal cortices of rats treated with $100 \mathrm{mg} / \mathrm{kg}$ body weight of $B$. coriacea when compared to the $\mathrm{NaN}_{3}$ group.

The cellular glutathione is the most abundant low molecular weight thiol involved in antioxidant defence in animal cells, and it is the 
major antioxidant compound that acts directly both in removing reactive oxygen species (ROS), and as a substrate for several peroxidases. In this study, the $\mathrm{NaN}_{3}$ group exhibited reduced GSH levels that was significant when compared to the control group and other groups treated with $B$. coriacea. This is suggestive of generation of ROS as a result of mitochondria dysfunction caused by $\mathrm{NaN}_{3}$ administration. Feoli et al. (2006) suggested that glutathione deficiency contributes to oxidative stress in many brain disorders, including seizure and stroke, as well as in neurodegenerative diseases such as Alzheimer's and Parkinson's diseases. Oxidative stress has been shown to affect several brain activities and promote long-term changes in multiple neural systems (Imbe et al., 2006).

On histologic examination with H\&E staining, apoptosis involves single cells or small clusters of cells (as shown by the black arrows around the degenerating neurons in the $\mathrm{NaN}_{3}$ treated group and the apoptotic cell appears as a round or oval mass, with dark eosinophilic cytoplasm and dense purple nuclear chromatin fragments). Furthermore, the cryptic changes seen in the Conflicts of Interest: None soma of pyramidal neurons of the $17 \mathrm{mg} / \mathrm{kg} \mathrm{NaN}$ adult treated group also suggests apoptotic mode of neuronal cell death, in which cell shrinkage made the cells smaller in size, with dense cytoplasm and the organelles more tightly packed. Similarly, neuronal apoptotic bodies have been described to consist of cytoplasm with tightly packed organelles, with or without a nuclear fragment (Stefanis et al., 1997). Cresyl fast violet staining for Nissl substance revealed a reduction in the staining intensity across all $\mathrm{NaN}_{3}$ treated groups when compared with the control. This is suggestive of decreased synthesis of proteins by the rough endoplasmic reticulum in the cells.

In conclusion Sodium azide at $17 \mathrm{mg} / \mathrm{kg}$ body weight had insulting effects on the prefrontal cortex microarchitecture of adult albino wistar rats as well as the expression and activities of certain enzymes, most probably due to oxidative stress and generation of free radicals. It is concluded that pre-treatment and post treatment with $B$. Coriacea resulted in the protection and reversal of the damaging effects of sodium azide respectively.

\section{REFERENCES}

1. Adisa RA, Choudhary MI, Olorunsogo OO. 2011. Hypoglycemic activity of Buchholzia coriacea (Capparaceae) seeds in streptozotocin-induced diabetic rats and mice. Experimental and toxicologic pathology. 30;63(7):619-25.

2. Adjanohoun J.E., Aboubakar N., Dramane K., Ebot M.E., Ekpere J.A., Enoworock E.G., Focho D., Gbile Z.O., Kamanyi A., Kamsu K.J., Keita A., Mbenkum T., Mbi C.N., Mbiele A.C., Mbome J.C., Muberu N.K., Nancy W.L., Kongmeneck B., Satabie B., Sowora A., Tamze V. and Wirmum C.K. (1996). Organization of African Unity; Scientific, Technical and Research Commission, editor. Traditional Medicine and Pharmacopoeia: Contribution to ethno botanical and floristic studies in Cameroon.

3. Ajaiyeoba EO, Onocha PA, Olarenwaju OT. 2001. Invitro anthelmintic properties of Buchholzia coriaceae and Gynandropsis gynandra extracts. Pharmaceutical Biology. 39(3):217-20.

4. Chang J, Yang JY, Choi J, Jung HH, IM GJ. 2011. Calcium imaging in gentamicin ototoxicity: Increased intracellular calcium relates to oxidative stress and late apoptosis. Int J Pediatr Otorhinolaryngol, 75(12): 1616-1622.

5. Enciu AM, Nicolescu MI, Manole CG, Mureşanu DF, Popescu LM, Popescu BO. 2011. Neuroregeneration in neurodegenerative disorders. BMC Neurol. 11-75. 
6. Engel L S, H Checkoway, M C Keifer, N S Seixas, W T Longstreth, Jr, K C Scott, K Hudnell, W K Anger and R Camicioli. 2001. Parkinsonism and occupational exposure to pesticides. Occup Environ Med 58: 582-589

7. Ennaceur A. 2010. One-trial object recognition in rats and mice: methodological and theoretical issues. Behav Brain Res. 215:244-254.

8. Ezekiel OO, Onyeoziri NF. 2009. Preliminary studies on the antimicrobial properties of. Buchholzia coriacea:472-4.

9. Feoli AM, Siqueira I, Almeida LM, Tramontina AC, Battu C, Wofchuk ST, Gottfried C, Perry ML, Gonçalves CA. 2006. Brain glutathione content and glutamate uptake are reduced in rats exposed to pre-and postnatal protein malnutrition. The Journal of nutrition. 136(9):2357-61.

10. Fischer A.H., Jacobson K., Rose J., Zeller R. 2008. Hematoxylin and Eosin (H \& E) staining, CSH Protoc.

11. Imbe H, Kimura A, Donishi T, Kaneoke Y. 2012. Chronic restraint stress decreases glial fibrillary acidic protein and glutamate transporter in the periaqueductal gray matter. Neuroscience. 223:209-18.

12. Jo YS, Park EH, Kim IH, Park SK, Kim H, Kim HT, Choi JS. 2007. The medial prefrontal cortex is involved in spatial memory retrieval under partial-cue conditions. Journal of Neuroscience. 27(49):13567-78.

13. Kadar A., Wittmann G., Liposits Z., Fekete C. 2009. Improved method for combination of immunocytochemistry and Nissl staining, J. neurosci. Methods.184:115-118.

14. Lapshak LJ, Luka CD, Nansah LS. 2016. The Effect of Aqueous Extract of Buchholzia coriacea Seeds on Some Biochemical Parameters in Normal and Alloxan-induced Diabetic Rats. International Journal of Biochemistry Research \& Review. 11(1):1.

15. Luques L, Shoham S, Weinstock M. 2007. Chronic brain cytochrome oxidase inhibition selectively alters hippocampal cholinergic innervation and impairs memory: Prevention by ladostigil. Exp Neurol; 206:209-219

16. Marino S, Marani L, Nazzaro C, Beani L, Siniscalchi A. 2007. Mechanisms of sodium azide-induced changes in intracellular calcium concentration in rat primary cortical neurons. Neurotoxicology; 28(3): 622-629.

17. Mbata TI, Duru CM, Onwumelu HA. 2009. Antibacterial activity of crude seed extracts of Buchholzia coriacea E. on some pathogenic bacteria. Journal of Developmental Biology and Tissue Engineering. 1(1):001-5

18. Moghadamtousi SZ, Rouhollahi E, Hajrezaie M, Karimian H, Abdulla MA, Kadir HA. 2015. Annona muricata leaves accelerate wound healing in rats via involvement of Hsp70 and antioxidant defence. International Journal of Surgery. 18:110-7.

19. O. O. Obembe, S. A. Onasanwo, Y. Raji. 2012. Preliminary study on the effects of Buchholzia Coriacea seed extract on male reproductive parameters in rats. Niger. J. Physiol. Sci. 165 - 169

20. Okolie Amanda, Obiudu I.K, Agbafor Kingsley, Unaegbu M.E, Godwill Engwa, Obiudu, C.V. 2015. Anti-Diabetic Property and Phytochemical Composition of Aqueous and Methanol Extracts of Buchholzia coriacea Seeds in Alloxan-Induced Diabetic Rats. Journal of Medical Sciences (Faisalabad); 15. 241-245.

21. Olayemi J.O, Akinola B.O, Ajao S.M, Enaibe B.U. 2016. Sodium azide-induced changes in the dorsolateral prefrontal cortex of rats: attenuating mechanisms of kolaviron, Eur. J. Anat. 20(1): 47-64

22. Safiulina D, Veksler V, Zharkovsky A, Kaasik A. 2006. Loss of mitochondrial membrane potential is associated with increase in mitochondrial volume: Physiological role in neurones. Journal of cellular physiology; 206(2):347-53. 
23. Smith RP, Louis CA, Kruszyna R, Kruszyna H. 1991. Acute neurotoxicity of sodium azide and nitric oxide. Fundam Appl Toxicol. 17(1):120-7

24. Stefanis L, Burke RE, Greene LA. 1997. Apoptosis in neurodegenerative disorders. Current opinion in neurology. 10(4):299-305.

25. Taglialatela G, Hogan D, Zhang WR, Dineley KT. 2009. Intermediate- and long-term recognition memory deficits inTg2576 mice are reversed with acute calcineurin inhibition. Behav Brain Res. 200:95-99.

26. Trushina E, Mcmurray CT. 2007. Oxidative stress and mitochondrial dysfunction in neurodegenerative diseases. Neuroscience, 145(4): 1233-1248. 